Abstracta Iranica Abstracta Iranica

Revue bibliographique pour le domaine irano-aryen

Volume 22 | 2001

Comptes rendus des publications de 1999

\title{
Truth and Narrative [50 The Untimely Thoughts of 'Ayn al-Qudàt al-Hamadānī. Richmond, Curzon Press, 1999, XX + 671 p.
}

\section{Pierre Lory}

\section{(2) OpenEdition}

\section{Journals}

Édition électronique

URL : http://journals.openedition.org/abstractairanica/36813

DOI : 10.4000/abstractairanica.36813

ISSN : 1961-960X

Éditeur :

CNRS (UMR 7528 Mondes iraniens et indiens), Éditions de l'IFRI

\section{Édition imprimée}

Date de publication : 15 mai 2001

ISSN : 0240-8910

\section{Référence électronique}

Pierre Lory, «Truth and Narrative 緊 The Untimely Thoughts of 'Ayn al-Quḍāt al-Hamadānī. Richmond, Curzon Press, 1999, XX + 671 p. », Abstracta Iranica [En ligne], Volume 22 | 2001, document 363, mis en ligne le 17 février 2010, consulté le 12 octobre 2020. URL : http://journals.openedition.org/ abstractairanica/36813; DOI : https://doi.org/10.4000/abstractairanica.36813

Ce document a été généré automatiquement le 12 octobre 2020.

Tous droits réservés 
Truth and Narrative ${ }_{20}^{\circ O}$ The Untimely Thoughts of 'Ayn al-Quḍāt al-Hamadānī . Richmond, Curzon Press, 1999, XX $+671 \mathrm{p}$.

Pierre Lory 
H. Dabashi offre ici une étude des plus approfondies sur l'œuvre et la pensée de 'Ayn alQuḍāt. Il reprend tous les documents pouvant aider à connaitre et comprendre l'auteur, son milieu, les directions de sa pensée et les raisons de son exécution. Cet ouvrage se démarque toutefois nettement d'autres travaux l'ayant précédé (R. Farmāniš, 1959 p. ex.) par une volonté de rupture méthodologique. L'ouvrage est parcouru par une critique insistante et acrimonieuse des orientalistes accusés d'« essentialiser » l'Orient et sa culture et d'enfermer les penseurs musulmans dans des cadres ternes et morts ${ }_{20}$ le cadre principal étant ici celui de la mystique. H. Dabashi affiche ici son intention d'inaugurer une nouvelle façon de découvrir le grand auteur que fut 'Ayn al-Qudāt : en le découvrant dans sa réalité concrète, en tâchant de découvrir sa subjectivité, l'élan vivant qui a animé toute son œuvre, sans se contenter de le situer dans une grille cloisonnée de disciplines ou une continuité d'auteurs et de traditions épistémologiques l'ayant précédé. Il met en relief l'étonnante indépendance d'esprit de 'Ayn al-Quḍāt, son goût du paradoxe, de l'ironie, voire de la provocation. Il y voit de sa part une façon de subvertir les mécanismes d'autorité qui s'étaient mis en place durant les premiers siècles de l'Islam, et d'affirmer une individualité autonome. La dimension proprement mystique de l'expérience du juge de Hamadān est atténuée au bénéfice d'une expérience de subjectivité. Dabashi insiste beaucoup sur la dimension littéraire de l'œuvre, sur les modes d'écriture où 'Ayn al-Quḍāt investissait sa passion et sa ferveur. $\mathrm{Au}$ total, nous avons un ouvrage vif, très stimulant, malgré des longueurs et des répétitions nombreuses, notamment dans l'introduction (63 p.) et le chapitre conclusif (64 p.), ainsi qu'une agressivité souvent superflue envers l'érudition universitaire occidentale.

INDEX

Thèmes : 8 . Soufisme

\section{AUTEURS}

PIERRE LORY

EPHE - Paris 